\title{
Identification of a Second Asian Soybean Rust Resistance Gene in Hyuuga Soybean
}

\author{
Mandy D. Kendrick, Donna K. Harris, Bo-Keun Ha, David L. Hyten, Perry B. Cregan, \\ Reid D. Frederick, H. Roger Boerma, and Kerry F. Pedley
}

First, sixth, and eighth authors: United States Department of Agriculture-Agricultural Research Service (USDA-ARS) Foreign DiseaseWeed Science Research Unit, Ft. Detrick, MD 21702; second, third, and seventh authors: Institute of Plant Breeding, Genetics \& Genomics, University of Georgia, Athens 30602; third author: Advanced Radiation Technology Institute (ARTI), Korea Atomic Energy Research Institute (KAERI), 1266, Sinjeong-dong, Jeongeup, Jeonbuk 580-185, South Korea; and fourth and fifth authors: USDA-ARS Soybean Genomics and Improvement Laboratory, Beltsville, MD 20705.

Accepted for publication 5 January 2011.

\begin{abstract}
Kendrick, M. D., Harris, D. K., Ha, B.-K., Hyten, D. L., Cregan, P. B., Frederick, R. D., Boerma, H. R., and Pedley, K. F. 2011. Identification of a second Asian soybean rust resistance gene in Hyuuga soybean. Phytopathology 101:535-543.

Asian soybean rust (ASR) is an economically significant disease caused by the fungus Phakopsora pachyrhizi. The soybean genes Rpp3 and Rpp?(Hyuuga) confer resistance to specific isolates of the pathogen. Both genes map to chromosome 6 ( $\mathrm{GmO6}$ ) (linkage group [LG] C2). We recently identified 12 additional soybean accessions that harbor ASR resistance mapping to $\mathrm{GmO6}$, within 5 centimorgans of Rpp3 and Rpp?(Hyuuga). To further characterize genotypes with resistance on

graphically diverse areas to inoculate plants and evaluate them for differential phenotypic responses. Three isolates elicited different responses from soybean accessions PI 462312 (Ankur) (Rpp3) and PI 506764 (Hyuuga) (Rpp?[Hyuuga]). In all, 11 of the new accessions yielded responses identical to either PI 462312 or Hyuuga and 1 of the new accessions, PI 417089B (Kuro daizu), differed from all others. Additional screening of Hyuuga-derived recombinant inbred lines indicated that Hyuuga carries two resistance genes, one at the Rpp3 locus on Gm06 and a second, unlinked ASR resistance gene mapping to Gm03 (LG-N) near Rpp5. These findings reveal a natural case of gene pyramiding for ASR resistance in Hyuuga and underscore the importance of utilizing multiple isolates of P. pachyrhizi when screening for ASR resistance.
\end{abstract} Gm06, we used a set of eight $P$. pachyrhizi isolates collected from geo-
Asian soybean rust (ASR) is an economically important disease due to the formidable threat it poses to the world's soybean crop. The causal agent of ASR is Phakopsora pachyrhizi Syd. and P. Syd., an obligate biotrophic fungus $(4,40,44)$. First identified in Japan in $1902(17,23)$, the pathogen has since been observed in all major soybean-growing regions of the world and has caused substantial economic damage to regions of Asia and South America over the past two decades $(26,45,47,48)$. In $2004, P$. pachyrhizi was identified for the first time in the continental United States (42), and the number of U.S. states in which the disease is present has increased annually to 20 states in 2009 $(7,13,21,26)$.

At $\approx 8$ days after infection by $P$. pachyrhizi, a susceptible soybean plant develops tan-colored (TAN) lesions on the leaf surface. The fungus produces uredinia, structures that give rise to asexual urediniospores, primarily on the abaxial surface of the leaf $(3,28)$. In susceptible plants, the accumulation of fungal mass that spreads throughout the leaf tissue can lead to defoliation $(2,3,12)$.

Corresponding author: K. F. Pedley; E-mail address: Kerry.Pedley@ars.usda.gov

The use of trade, firm, or corporation names in this publication is for the information and convenience of the reader. Such use does not constitute an official endorsement or approval by the United States Department of Agriculture or the Agricultural Research Service of any product or service to the exclusion of others that may be suitable.

doi:10.1094/PHYTO-09-10-0257

This article is in the public domain and not copyrightable. It may be freely reprinted with customary crediting of the source. The American Phytopathological Society, 2011
Fungicide application is the most commonly employed management practice used in protecting and treating soybean crops against ASR (12). Such treatments can be effective but are economically and environmentally costly. Success depends on the timing of the treatment (application later in the growing season is less effective) and on environmental conditions at the time of application (39). An attractive alternative to fungicide use is the development of adapted soybean cultivars with resistance to $P$. pachyrhizi.

Two types of ASR resistance have been observed in soybean germplasm screens (3). In the immune reaction (IM), no visible lesions appear on the surface of an infected soybean leaf, a consequence of three to four host cells rapidly collapsing and restricting fungal growth (31). The second type of resistance is marked by the appearance of reddish brown (RB) lesions on the host leaf, resulting from a somewhat delayed inhibition of fungal growth relative to the IM reaction (31). In some instances, uredinia develop in the RB lesions and produce urediniospores but the number of uredinia formed is greatly reduced (31).

Five ASR resistance genes, which recognize specific isolates of P. pachyrhizi, have been identified in soybean. Resistance to Phakopsora pachyrhizi-1 (Rppl), identified in the plant introduction (PI) 200492 (also referred to as Komata), confers an IM reaction (19,32). Accession PI 230970 produces RB lesions in response to select isolates of $P$. pachyrhizi and carries Rpp2 $(16,43)$. PI 459025B (Bing nan) forms RB lesions with resistance conferred by Rpp4, which encodes a coiled-coil nucleotidebinding site leucine-rich repeat (CC-NBS-LRR) protein $(15,34)$. Accessions PI 200456 (Awashima Zairai), PI 200487 (Kinoshita), PI 200526 (Shira Nuhi), and PI 471904 (Orba) are collectively referred to as Rpp5 lines, because ASR resistance of these acces- 
sions maps to the same region on Gm03 (linkage group [LG]-N). All of the Rpp genes are dominant except for $r p p 5$, which is a recessive allele in PI 200456 (11).

Rpp3, identified in the accession PI 462312 (Ankur), is a dominant resistance gene that maps to $\mathrm{Gm06}$ between markers Satt460 and Sat_263 on LG-C2 (16,20). The resistance gene Rpp?(Hyuuga) from the accession PI 506764 (Hyuuga) maps to the same chromosome, between markers STS70887 and STS70923 (37,38).

Recently, Hyuuga, PI 462312, and two of the Rpp5 lines (PI 200487 and PI 471904) were shown to have identical singlenucleotide polymorphism (SNP) haplotypes at five nucleotides on Gm06 relative to 38 other soybean cultivars tested (37). These identical SNP haplotypes suggest that Rpp3, Rpp?(Hyuuga), and the allele at the Rpp3 locus in PI 200487 and PI 471904 may originate from the same genetic background (37). Hyuuga (Rpp?[Hyuuga]) and PI 462312 (Rpp3) had similar reaction phenotypes when inoculated with 10 different isolates and one field sample of $P$. pachyrhizi $(20,38)$. However, the resistance in PI 462312 (Rpp3) has been defeated in Brazilian field studies while Hyuuga (Rpp?[Hyuuga]) has maintained resistance (43). It remains unknown whether Rpp3 and Rpp?(Hyuuga) are alleles or tightly linked genes or whether Hyuuga carries the Rpp3 gene and a second, unlinked gene that confers resistance to the Brazilian field isolate.

In this study, we evaluated 12 additional soybean accessions with ASR resistance that maps to Gm06, similar to Rpp3 and $R p p$ ?(Hyuuga). Our objective was to delineate ASR resistance on Gm06 by inoculating these 12 soybean accessions, as well as PI 462312 (Rpp3) and Hyuuga (Rpp?[Hyuuga]), with eight isolates of $P$. pachyrhizi and comparing their reaction phenotypes.

\section{MATERIALS AND METHODS}

Pathogen isolates. The P. pachyrhizi isolates used in this study, with the exception of Colombia 04-2 (CO04-2) and Vietnam 05-1 (VT05-1), have been described previously $(20,41)$. Isolate CO042 was collected in 2004 from Armenia, Quindío, Colombia, and VT05-1 was collected in 2005 from Hanoi, Vietnam. The $P$. pachyrhizi isolates (Table 1) were propagated by inoculating the susceptible soybean 'Williams 82' and collecting urediniospores using a mechanical harvester (6). The urediniospores were then stored under liquid nitrogen at the United States Department of Agriculture-Agricultural Research Service (USDA-ARS) Foreign Disease-Weed Science Research Unit (FDWSRU) Biological

TABLE 1. Phakopsora pachyrhizi isolates used in this study to inoculate soybean lines

\begin{tabular}{lllcl}
\hline & & \multicolumn{3}{c}{ Year } \\
Isolate & \multicolumn{1}{c}{ Country } & \multicolumn{1}{c}{ Location } & collected & \multicolumn{1}{c}{ Source } \\
\hline CO04-2 & Colombia & Armenia, Quindio & 2004 & R. Tisnes $^{\mathrm{a}}$ \\
HW98-1 & United States & Oahu & 1998 & E. Kilgore $^{\mathrm{b}}$ \\
IN73-1 & India & Pantnagar & 1973 & D. N. Thapliyal \\
LA04-1 & United States & Ben Hur, Louisiana & 2004 & R. Schneider \\
SA01-1 & South Africa & Natal Province & 2001 & Z. A. Pretorius \\
TW72-1 & Taiwan & Taipei & 1972 & L.-C. Wu \\
VT05-1 & Vietnam & Hanoi & 2005 & B. Nguyen \\
ZM01-1 & Zimbabwe & Harare & 2001 & C. Levy \\
\hline
\end{tabular}

a Valle del Cauca, Calcedonia, Colombia.

b Hawaii Department of Agriculture, Hilo.

c Govind Ballabh Pant University of Agriculture and Technology, Pantnagar, India.

${ }^{\mathrm{d}}$ Department of Plant Pathology and Crop Physiology, Louisiana State University, Baton Rouge.

e Department of Plant Sciences, University of the Free State, Bloemfontein, South Africa.

f Asian Vegetable Research and Development Center, Taipei, Taiwan.

g Vietnam Agricultural Science Institute, Hanoi, Vietnam.

${ }^{\mathrm{h}}$ Commercial Farmers Union of Zimbabwe, Harare, Zimbabwe.
Safety Level-3 Plant Pathogen Containment Facility (BSL-3P) at Fort Detrick, Maryland (33).

Plant materials. The soybean genotypes used in this study include the susceptible Williams 82 and 'Dillon', PI 462312 (Rpp3) (16), Hyuuga (Rpp?[Hyuuga]), $97 \mathrm{~F}_{6}$-derived recombinant inbred lines (RILs) developed from crossing Dillon $\times$ Hyuuga (38), and the four Rpp5 lines: PI 200456, PI 200487, PI 200526, and PI 471904 (11). Twelve additional accessions come from the 805 lines that were initially identified in an ASR resistance screen of 16,595 soybean accessions from the USDA Soybean Germplasm Collection (University of Illinois) (36). These 805 lines were screened in the field at Attapulgus, GA in 2005 and 2006, with a combination of natural infection and artificial spore inoculations of $P$. pachyrhizi, and in a greenhouse in Griffin, GA in 2006, with a sample of $P$. pachyrhizi collected from soybean and kudzu in Georgia in 2005 and 2006 (46). This screening identified 18 ASR-resistant accessions: PI 200488, PI 416826A, PI 416873B, PI 417089B, PI 417120, PI 417503, PI 476905A, PI 567024, PI 567059, PI 605829, PI 605838, PI 605854B, PI 605773, PI 605865B, PI 605885B, PI 605891A, PI 606405, and PI 615437. These ASR-resistant accessions were used as male parents and crossed to the ASR-susceptible 'Boggs' (PI 417503, PI 567059, PI 605773, PI 605829, PI 605838, PI 605854B, PI 605865B, PI 605885B, PI 605891A, PI 606405, and PI 615437) and '5601T' (PI 476905A) or the ASR-susceptible breeding line G00-3880 (PI 200488, PI 416826A, PI 416873B, PI 417089B, PI 417120 , and PI 567024). The $F_{2}$ or $F_{2: 3}$ populations derived from these crosses were screened in the Griffin, GA greenhouse using P. pachyrhizi samples collected in 2007 and 2008 from soybean and kudzu in Georgia. From each of the $\mathrm{F}_{2}$ or $\mathrm{F}_{2: 3}$ populations, a resistant bulk was created by sampling a single leaf from at least 12 resistant $F_{2}$ plants or a composite from 12 homozygous resistant $\mathrm{F}_{2: 3}$ lines (from each line, a single leaf was sampled from at least eight $\mathrm{F}_{3}$ plants) and a susceptible bulk was created by sampling a single leaf from at least 12 susceptible $F_{2}$ plants or a composite from 12 homozygous susceptible $\mathrm{F}_{2: 3}$ lines (from each line, a single leaf was sampled from at least eight $F_{3}$ plants), along with 12-plant composite samples of the resistant parent and the susceptible parent. The DNA from the four 12-plant composites was extracted using a modified hexadecyltrimethylammonium acid protocol (22) and resuspended in Tris-EDTA buffer, $\mathrm{pH}$ 8.0. These DNA samples were sent to the USDA-ARS Soybean Genomics and Improvement Laboratory, Beltsville, MD for evaluation with a 1,536 SNP assay (18). This bulk segregant analysis (BSA) approach (35) provided information on the genomic location of the ASR resistance gene in each PI and was carried out as described by Hyten et al. (20). Seed for all lines inoculated in the FDWSRU containment facility, except the RILs, were sown three seeds per pot in 9-by-9-cm pots (T. O. Plastics, Clearwater, MN) filled with Sunshine Mix1/LC1 (Sun-Grow Horticulture Products, Belleview, VA) and thinned to two plants after germination. For each inoculation experiment, two pots of each soybean line were planted. The pots containing plants to be inoculated with the same fungal isolate were randomly arranged in 38-by-47-cm flats (Hummert International, Earth City, MO) during and after inoculation. A replicate set of plants was set up in exactly the same fashion. The RILs were sown one seed per cell, alongside Dillon, Hyuuga, and PI 462312, in 72-cell flats (Hummert International, Earth City, MO), with each row of 12 cells containing seed from one RIL. All plants were grown in the greenhouse under $16 \mathrm{~h}$ of light, fertilized with 14-14-14 Osmocote (Scotts-Sierra Horticultural Products, Co., Marysville, $\mathrm{OH}) 1$ week following germination, and, after 3 weeks, transferred to the BSL-3P (33) for inoculations.

Inoculation. The day before inoculations, $50 \mathrm{mg}$ of urediniospores from each of the eight $P$. pachyrhizi isolates were removed from liquid nitrogen. The spores were heat shocked at $40^{\circ} \mathrm{C}$ for $5 \mathrm{~min}$ and placed into a weigh boat, where they were left to 
hydrate overnight by floating the weigh boat on water and in an enclosed petri dish in the dark at room temperature. The inoculum for each isolate was prepared by suspending the urediniospores in $7.5 \mathrm{ml}$ of $0.1 \%$ Tween 20 in sterile distilled water, mixing vigorously, and bringing the total volume up to $150 \mathrm{ml}(300 \mathrm{ml}$ when screening the RILs) with sterile distilled water. Spore concentrations were determined via hemacytometer measurements and were 67,000 to 236,000 spores $\mathrm{ml}^{-1}$. Each inoculum was applied with an atomizer. Spore viability counts were determined by spraying inoculum of each isolate onto the surface of sterile $2 \%$ agar media (in petri dishes) and allowing the dish to incubate overnight at $20^{\circ} \mathrm{C}$. The plates were analyzed the next day using $\times 100$ magnification to assess spore germination. Germination rates were 45 to $95 \%$. After inoculations, the RILs were incubated in a single dew chamber for $24 \mathrm{~h}$, with temperatures of 20 to $21^{\circ} \mathrm{C}$ between replicates. For experiments using the eight isolates, the inoculations were performed on the same day. Following the spray inoculations, the plants were divided into two identical sets so that the replicate soybean lines treated with the same fungal isolate could be incubated in separate dew chambers. Each set was incubated in a large dew chamber for $24 \mathrm{~h}$ with temperatures of 19 to $22^{\circ} \mathrm{C}$. A replicate was performed in the same fashion. Following inoculations and overnight incubations in the dew chambers, plants were then moved into a greenhouse where supplemental illumination was provided by $1,000-\mathrm{W}$ metalarc lights (Sylvania, Danvers, MA). Pots were placed in metal trays and watered from the bottom.

Disease ratings. Soybean leaves were evaluated 14 days after inoculation for reaction phenotypes. Lesions were recorded as $\mathrm{RB}$, TAN, or intermediate (INT), between RB and TAN. The INT lesions were darker in color than TAN lesions but appeared to be smaller and have more sporulation than the RB lesions. To verify reaction phenotypes, a subset of leaves was collected from individual plants, analyzed, and photographed with a Nikon SMZ1000 stereoscope fitted with the DS-5M camera head and DS-L1 camera control unit (Nikon Instruments Inc., Melville, NY).

Mapping resistance genes. In total, 97 RILs of Dillon $\times$ Hyuuga were used in this study. This population was previously genotyped with 138 polymorphic simple-sequence repeat (SSR) markers across the 20 soybean chromosomes in the study of
Monteros et al. (38). Map Manager QTXb20 (27) was used with the Kosambi mapping function (24) to determine the linkage of SSR markers and lesion types of RILs. Seven additional SSR markers were added to the Gm03 (LG-N) linkage map of the Dillon $\times$ Hyuuga population reported by Monteros et al. (38).

\section{RESULTS}

Identification of 12 ASR-resistant cultivars that map to LGC2. Of the 805 soybean accessions previously identified as having ASR resistance (36), 18 were rescreened and found to have resistance to the $P$. pachyrhizi population in Georgia. The $\mathrm{F}_{2}$ plants or $\mathrm{F}_{2: 3}$ families derived from each of these 18 PIs crossed to the ASR-susceptible Boggs, 5601T, or G00-3880 were screened for ASR resistance and segregated in a 3:1 resistant/susceptible ratio. The resistance gene in each PI line was mapped using BSA (18).

Of the 18 resistant PIs identified in the field and greenhouse, 12 (PI 416873B, PI 417089B, PI 417503, PI 567024, PI 567059, PI 605829, PI 605838, PI 605854B, PI 605865B, PI 605891A, PI 606405, and PI 615437) were found to possess an ASR resistance gene on Gm06, within 5 centimorgans (cM) of Rpp3 and Rpp?(Hyuuga) in the 105- to 110 -cM interval on the USDA consensus map $4.0(18,20,37,38)$. The BSA putatively identified resistance genes on other chromosomes in PI 200488, PI 416826A, PI 417120, PI 476905A, PI 605773, and PI 605885B. The linkage mapping of the potentially new ASR resistance genes from these six PIs is currently underway at the University of Georgia.

To further characterize PI 462312 (Rpp3), Hyuuga (Rpp?[Hyuuga]), and the 12 accessions with ASR resistance mapping to Gm06, the lines were inoculated with eight different isolates of P. pachyrhizi (Table 1) and rated for differential reaction phenotypes. $P$. pachyrhizi isolates IN73-1, LA04-1, SA01-1, and TW72-1 were included to confirm reaction phenotypes observed in previous experiments (20), in which there were no differences between PI 462312 (Rpp3) and Hyuuga (Rpp?[Hyuuga]) plants. Four additional isolates (ZM01-1, CO04-2, VT05-1, and HW98-1) which had not previously been used for differentiation between PI 462312 and Hyuuga were selected for inoculations based on sequence divergence (1).

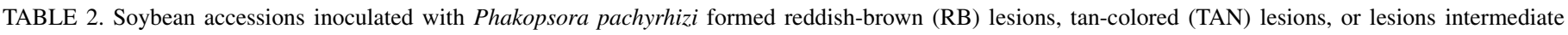
(INT) between RB and TAN that were analyzed 14 days after inoculation

\begin{tabular}{|c|c|c|c|c|c|c|c|c|}
\hline \multirow[b]{2}{*}{ Entry (gene) } & \multicolumn{8}{|c|}{ Isolates $^{\mathrm{a}}$} \\
\hline & $\mathrm{CO} 04-2$ & HW98-1 & IN73-1 & LA04-1 & SA01-1 & TW72-1 & VT05-1 & ZM01-1 \\
\hline Williams 82 & TAN & TAN & $\mathrm{TAN}^{\mathrm{b}}$ & TAN & TAN & $\mathrm{TAN}^{\mathrm{b}}$ & $\mathrm{TAN}^{\mathrm{b}}$ & TAN \\
\hline PI $462312(R p p 3)$ & $\mathrm{TAN}^{\mathrm{b}}$ & $\mathrm{RB}$ & $\mathrm{RB}$ & $\mathrm{RB}$ & $\mathrm{RB}$ & TAN & TAN & TAN \\
\hline Hyuuga (Rpp?[Hyuuga]) & $\mathrm{RB}^{\mathrm{b}}$ & $\mathrm{RB}$ & $\mathrm{RB}$ & $\mathrm{RB}$ & $\mathrm{RB}$ & TAN & $\mathrm{RB}$ & $\mathrm{RB}$ \\
\hline PI $416873 B$ & TAN & $\mathrm{RB}$ & RB & $\mathrm{RB}$ & $\mathrm{RB}$ & TAN & $\mathrm{TAN}^{\mathrm{c}}$ & $\mathrm{TAN}^{\mathrm{c}}$ \\
\hline PI 417089B & INT & $\mathrm{INT}^{\mathrm{d}}$ & INT $^{\mathrm{d}}$ & $\mathrm{INT}^{\mathrm{b}}$ & $\mathrm{RB}^{\mathrm{b}}$ & $\mathrm{INT}^{\mathrm{e}}$ & INT & INT \\
\hline PI 417503 & TAN & $\mathrm{RB}$ & $\mathrm{RB}$ & $\mathrm{RB}$ & $\mathrm{RB}$ & TAN & $\mathrm{TAN}^{\mathrm{c}}$ & $\mathrm{TAN}^{\mathrm{c}}$ \\
\hline PI 567024 & $\mathrm{RB}^{\mathrm{f}}$ & $\mathrm{RB}$ & $\mathrm{RB}^{\mathrm{b}}$ & $\mathrm{RB}$ & $\mathrm{RB}^{\mathrm{b}}$ & TAN & $\mathrm{RB}^{\mathrm{b}}$ & $\mathrm{RB}$ \\
\hline PI 567059 & TAN & $\mathrm{RB}$ & $\mathrm{RB}$ & $\mathrm{RB}$ & $\mathrm{RB}$ & TAN & $\mathrm{TAN}^{\mathrm{c}}$ & $\mathrm{TAN}^{\mathrm{c}}$ \\
\hline PI 605829 & TAN & $\mathrm{RB}$ & $\mathrm{RB}$ & $\mathrm{RB}$ & $\mathrm{RB}$ & TAN & $\mathrm{TAN}^{\mathrm{c}}$ & $\mathrm{TAN}^{\mathrm{c}}$ \\
\hline PI 605838 & TAN & $\mathrm{RB}$ & $\mathrm{RB}$ & $\mathrm{RB}$ & $\mathrm{RB}$ & TAN & TAN & TAN \\
\hline PI 605854B & TAN & $\mathrm{RB}$ & $\mathrm{RB}$ & $\mathrm{RB}$ & $\mathrm{RB}$ & TAN & TAN & TAN \\
\hline PI 605865B & TAN & $\mathrm{RB}$ & $\mathrm{RB}$ & $\mathrm{RB}$ & $\mathrm{RB}$ & TAN & TAN & TAN \\
\hline PI 605891A & TAN & $\mathrm{RB}$ & $\mathrm{RB}$ & $\mathrm{RB}^{\mathrm{b}}$ & $\mathrm{RB}$ & TAN & TAN & TAN \\
\hline PI 606405 & TAN & $\mathrm{RB}$ & $\mathrm{RB}$ & $\mathrm{RB}$ & $\mathrm{RB}$ & TAN & $\mathrm{TAN}^{\mathrm{c}}$ & $\mathrm{TAN}^{\mathrm{c}}$ \\
\hline PI 615437 & TAN & $\mathrm{RB}$ & $\mathrm{RB}$ & $\mathrm{RB}$ & $\mathrm{RB}^{\mathrm{f}}$ & TAN & TAN & TAN \\
\hline
\end{tabular}

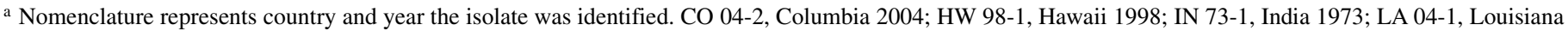
2004; SA 01-1, South Africa 2001; TW 72-1, Taiwan 1972; VT 05-1, Vietnam 2005; and ZM 01-1, Zimbabwe 2001. Data based on eight plants unless otherwise noted.

b Data based on seven plants scored in the two replicates per trial.

${ }^{c}$ Data based on six plants scored in one trial.

${ }^{\mathrm{d}}$ Data based on six plants scored in the two replicates per trial.

e Trial was replicated a third time to ensure scoring results.

f Data based on five plants scored in the two replicates per trial. 
The reaction phenotypes of each soybean line are shown in Table 2. Consistent with previous reports, isolates IN73-1, LA04-1, and SA01-1 elicited RB responses on both PI 462312 and Hyuuga plants. Eleven of the new ASR-resistant accessions also produced RB lesions to these three isolates, while 1 of the new accessions, PI 417089B, had lesions that were INT for all isolates tested except SA01-1 (data not shown). With the exception of PI 417089B, all of the accessions formed TAN lesions when inoculated with TW72-1 (Fig. 1).
HW98-1 elicited RB lesions on all soybean accessions except PI 417089B. Three P. pachyrhizi isolates (CO04-2, VT05-1, and ZM01-1) elicited differential responses among the soybean accessions tested (Fig. 1 and data not shown). Hyuuga and the new accession PI 567024 formed RB lesions following inoculation with CO04-2, VT05-1, or ZM01-1. These three isolates elicited INT lesions on PI 417089B plants and TAN lesions on the 11 other accessions, including PI 462312 (Rpp3). Collectively, these data suggest that the 14 soybean lines screened represent at

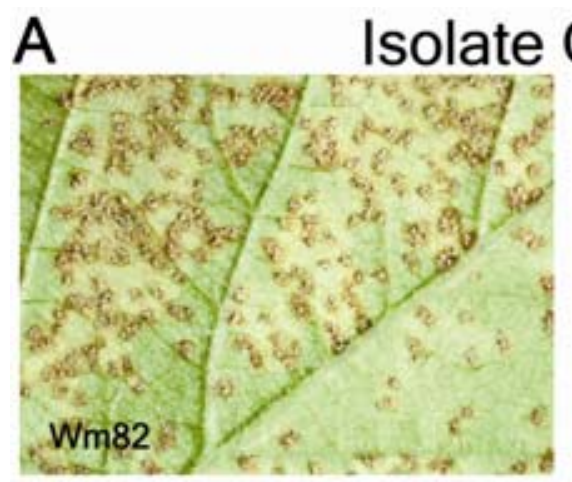

CO04-2
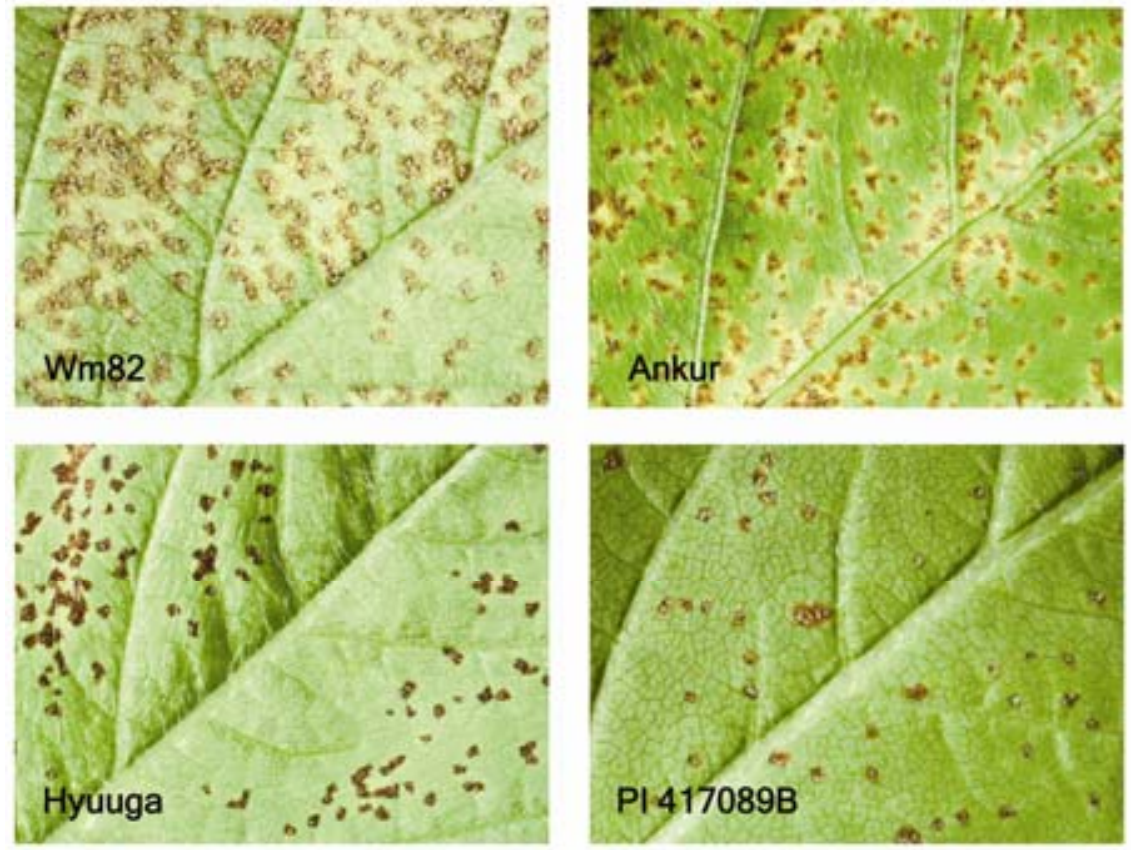

\section{B Isolate TW72-1}
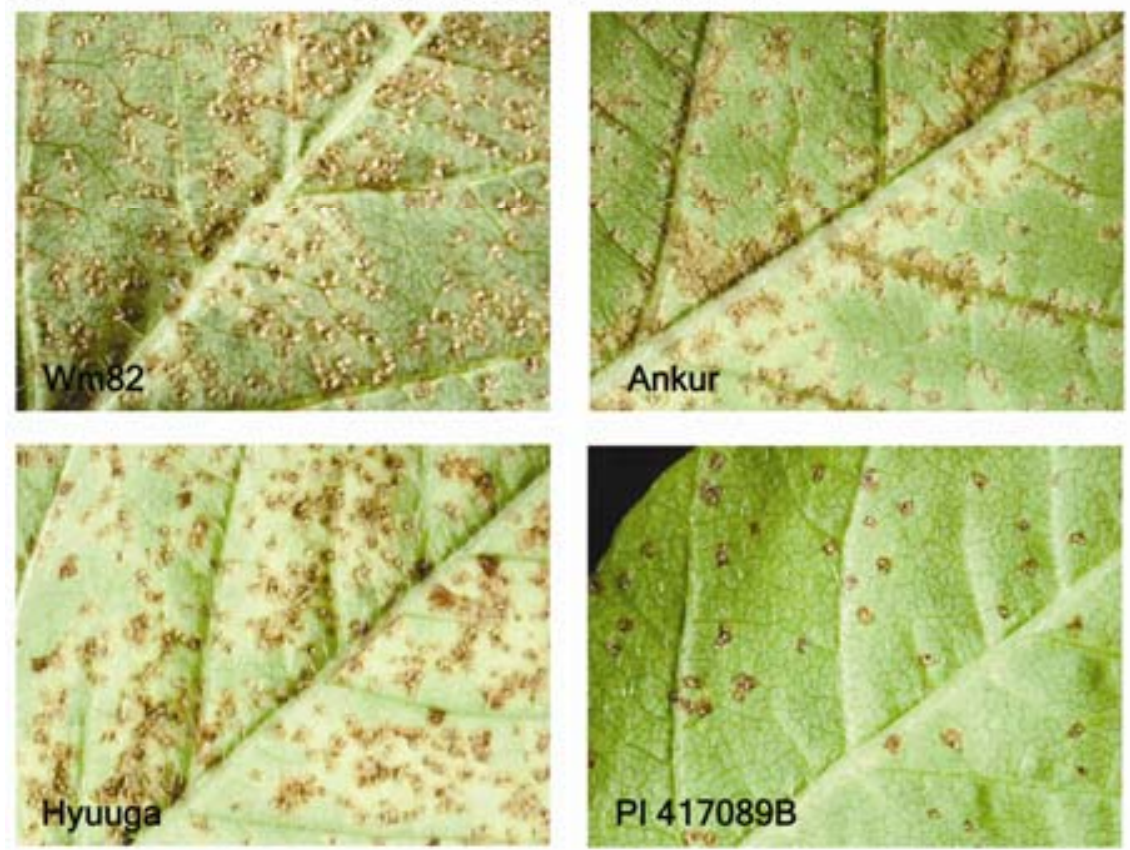

Fig. 1. Differential lesion phenotypes of soybean accessions inoculated with Phakopsora pachyrhizi isolates TW72-1 and CO04-2. A, Wm82 (top left) and plant introduction (PI) 462312 (Rpp3) (top right) develop tan-colored (TAN) lesions when inoculated with P. pachyrhizi isolate CO04-2 while Hyuuga (Rpp? [Hyuuga]) (bottom left) has reddish-brown (RB) lesions. PI 417089B (bottom right) has lesions that are intermediate (INT) between the TAN and RB phenotypes. B, Plants infected with P. pachyrhizi isolate TW72-1; photos are in the same order as in A. Wm82, PI 462312, and Hyuuga develop TAN lesions while PI 417089B forms INT lesions. Photos were taken of the adaxial surface of soybean leaves 16 days after inoculation. 
least three different types of ASR resistance: PI 417089B-like, Hyuuga-like, and PI 462312-like. The resistance observed in PI 417089B seems to be unique; therefore, we focused on resolving the differences between Hyuuga and PI 462312.

Hyuuga carries two ASR resistance genes. The differential responses observed in Hyuuga and PI 462312 could be driven by different alleles of the same resistance locus or tightly linked resistance genes on Gm06. Because Hyuuga has resistance to all of the isolates that PI 462312 is resistant to but also recognizes isolates that PI 462312 is susceptible to, a third hypothesis is that Hyuuga carries Rpp3 and a second, unlinked ASR resistance gene, which conditions resistance to additional isolates such as ZM01-1, VT05-1, and CO04-2, and the previously described Brazilian field isolate (11). This latter possibility was tested by inoculating a previously developed $\mathrm{F}_{6}$-derived RIL population from the cross of Hyuuga to the susceptible parent Dillon (38), with $P$. pachyrhizi isolate CO04-2 that differentiated PI 462312 and Hyuuga. Previously, 117 RILs were inoculated with urediniospores collected from Georgia field samples (GFS) in 2005 $(37,38)$. Both Hyuuga (Rpp?[Hyuuga]) and PI 462312 (Rpp3) produce RB lesions when challenged with GFS. Therefore, PI 462312- and Hyuuga-mediated resistance could not be differentiated in this study, and the Rpp?(Hyuuga) map position on Gm06 could either be a result of Rpp3 and Rpp?(Hyuuga) being a different allele at the Rpp3 locus, or Rpp?(Hyuuga) being a second locus which is tightly linked to Rpp3. Initially, we used isolate CO04-2 to inoculate 29 of these RILs that were previously shown to be resistant to the GFS of $P$. pachyrhizi. In total, 10 lines
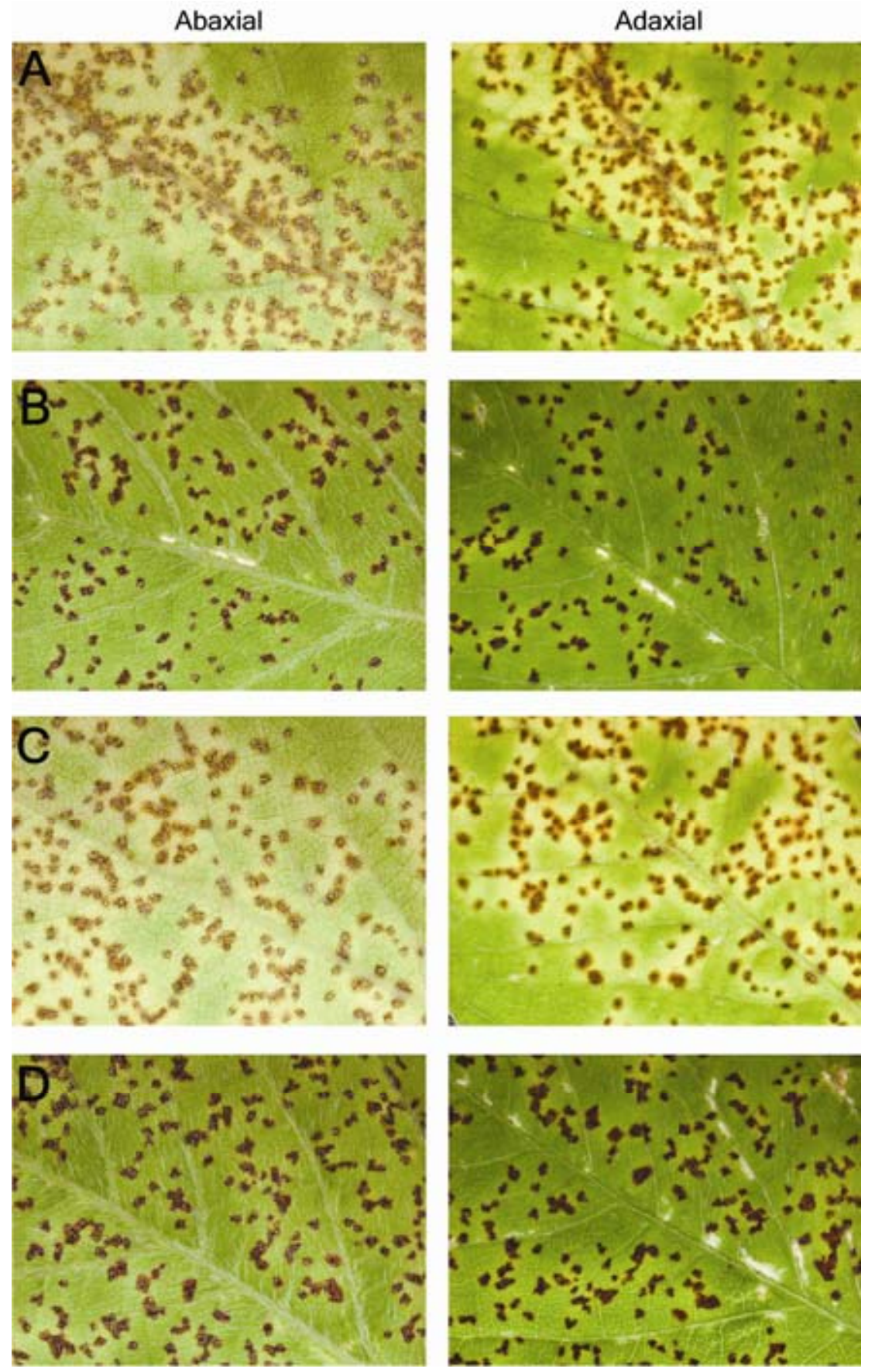

Fig. 2. $\mathrm{F}_{6}$-derived recombinant inbred lines (RILs) that were derived from a cross of Hyuuga to the susceptible parent Dillon and were resistant to a Georgia field sample of Phakopsora pachyrhizi were screened with isolate CO04-2. A, Dillon is the susceptible parent of the RILs and $\mathbf{B}$, Hyuuga is the resistant parent. C and D, $\mathrm{F}_{6: 7}$ plants from two RILs that were resistant to the Georgia field isolate. C, G01-PR89 displays the susceptible tan-colored lesions to the CO04-2 isolate while D, GO1-PR86 displays the resistant reddish-brown lesions. Photos were taken 14 days after inoculation. 
had RB lesions like Hyuuga plants, while 13 lines had TAN lesions like PI 462312 (Fig. 2). Six RILs had mixed populations, with most plants displaying TAN or RB lesions. Previous analysis of the 117 RILs by Monteros et al. (38) revealed that $\approx 4 \%$ of the RILs resulted from residual heterozygosity present in the original $\mathrm{F}_{6}$ plant; therefore, we expected 1 or 2 heterogeneous lines out of the 29 RILs scored for lesion type (38). In four of the six RILs analyzed here, $>75 \%$ of the plants had RB lesions. We speculate that the remaining $25 \%$ of plants from each line, having TAN lesions, were the result of seed contamination and reclassified the four lines as RB for mapping. The other two RILs had ratios of $71 \%$ of plants with RB lesions to $29 \%$ plants with TAN lesions and $63 \%$ TAN to $37 \% \mathrm{RB}$, respectively, and we arbitrarily classified these two lines as heterogeneous for mapping. Given that all of these RILs were classified as resistant to the GFS of $P$. pachyrhizi but only approximately half of them were resistant to the CO04-2 isolate, it is likely that Hyuuga's resistance to CO04-2 is conditioned by a second resistance gene independent of Rpp?(Hyuuga).

In order to map this second ASR resistance gene in Hyuuga, 68 additional RILs were screened with the CO04-2 isolate. In total, 40 lines had TAN lesions, 34 lines produced RB lesions, and 23 lines displayed a mixture of TAN and RB lesions in response to CO04-2. Of these 23 RILs, 7 had $>75 \%$ of the plants producing TAN lesions and were reclassified as TAN for mapping purposes. In all, 11 of the 23 lines had $>75 \%$ of the plants with RB lesions and were likewise classified as RB. We speculate that the re- maining plants are the result of seed contamination. We were unable to clearly define five of these lines as producing either RB or TAN lesions and classified them as heterogeneous for the mapping study. Using previously developed SSR markers $(18,37)$, the second ASR resistance locus in Hyuuga, associated with RB lesions (upon inoculation with $\mathrm{CO} 04-2$ ), was mapped to $\mathrm{GmO3}$ (LG-N), between markers SSR03-866 and SSR03-940 (Fig. 3). This is the same chromosome and genomic region that contains the Rpp5 genes (11).

Soybean accessions PI 471904 and PI 200487 react similarly to Hyuuga. To further characterize the Hyuuga- and Rpp5mediated ASR resistance, we inoculated the Rpp 5 accessions with the same eight isolates of P. pachyrhizi (listed in Table 1). Two of the four Rpp5 lines, PI 471904 and PI 200487, reacted similarly to Hyuuga (Table 3) (one out of eight PI 200487 and Hyuuga plants yielded TAN lesions when inoculated with CO04-2, while all PI 471904 plants displayed RB lesions). All three soybean accessions produced RB lesions when inoculated with $P$. pachyrhizi isolates HW98-1, IN73-1, LA04-1, SA01-1, VT05-1, and ZM01-1. PI 200456 carries the recessive rpp5 gene, and the accession produced TAN lesions when inoculated with IN73-1 and LA04-1 but was heterogeneous with both RB and TAN lesions following inoculations with CO04-2, HW98-1, SA01-1, VT05-1, and ZM01-1 (Table 3). PI 200526, which also has resistance mapping to the Rpp5 genomic region, was susceptible to all isolates tested.
A

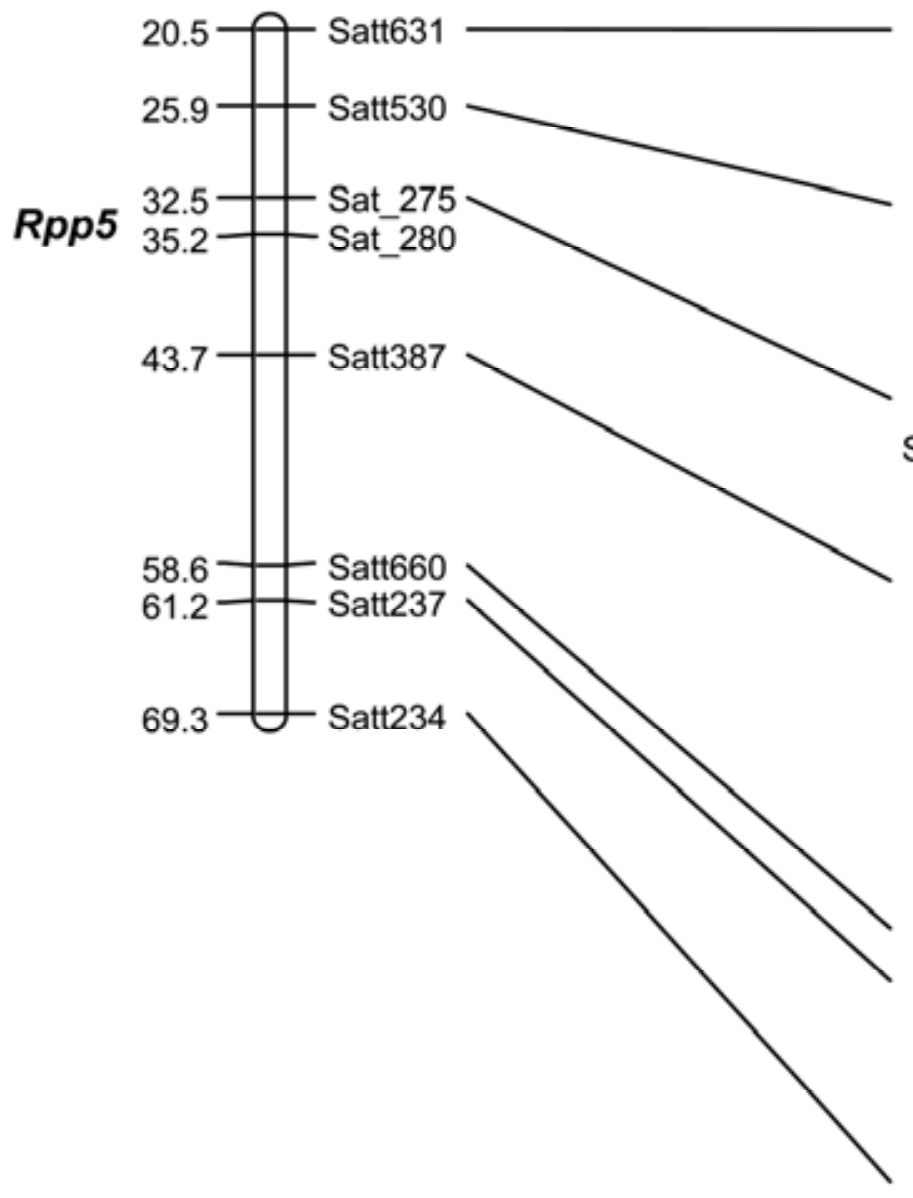

B

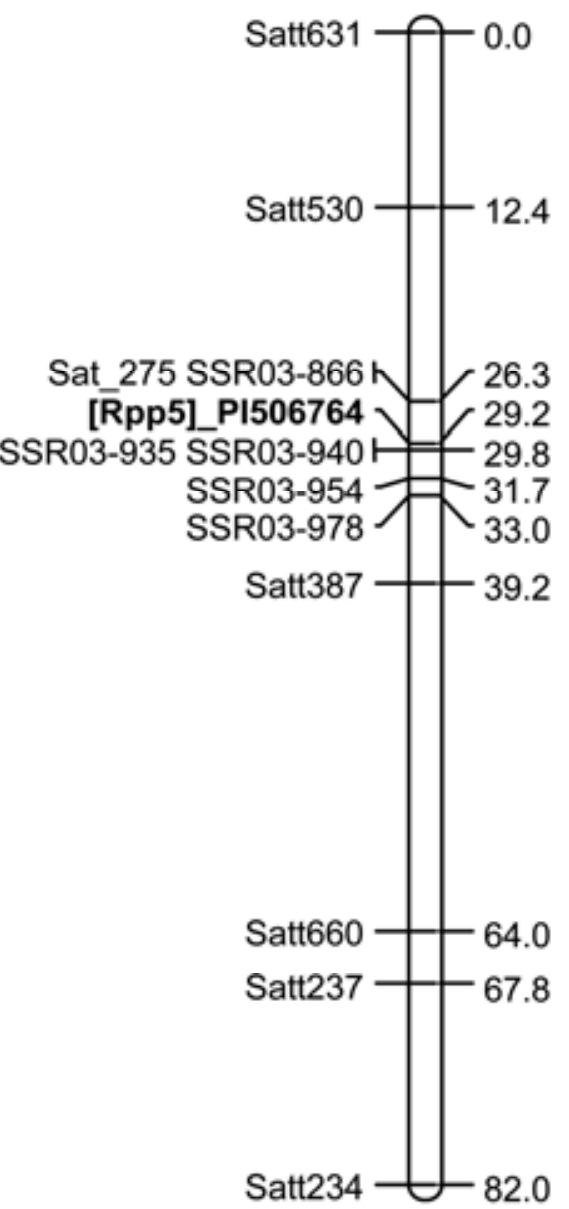

Fig. 3. Genetic linkage map of a fragment of soybean linkage group $\mathrm{N}$ on chromosome 3, which contains the second Hyuuga gene, [Rpp5]_PI 506764. A, Soybean consensus genetic map (18) showing the position of the Rpp5 locus (or loci). B, Genetic map derived from screening 97 Hyuuga (resistant) $\times$ Dillon (susceptible) $\mathrm{F}_{6}$-derived recombinant inbred lines with Phakopsora pachyrhizi isolate CO04-2 and with the map position of [Rpp5]_PI 506764 indicated. Values on the left side in $\mathrm{A}$ and the right side in $\mathrm{B}$ represent genetic distance in centimorgans. 


\section{DISCUSSION}

Presently, no soybean genes have been identified that confer resistance to all isolates of $P$. pachyrhizi (14); therefore, studies to identify additional sources of ASR resistance continue $(11,36,46)$. In this study, ASR resistance genes in 12 soybean PIs were identified by BSA on Gm06 (LG-C2), near Rpp3 and Rpp?(Hyuuga). By inoculating PI 462312 (Rpp3), Hyuuga (Rpp?[Hyuuga]), and each of the newly identified PIs with eight geographically diverse $P$. pachyrhizi isolates (Table 1), the accessions could be grouped based on reaction phenotypes (Table 2). In all, 10 soybean accessions responded similarly to PI 462312 (Rpp3) and 1 similarly to Hyuuga (Rpp?[Hyuuga]). Accession PI 417089B displayed INT lesions when inoculated with all isolates except SA04-1. In the recent screen of the USDA Soybean Germplasm Collection, PI 417089B was scored as TAN in the first trial and $\mathrm{RB}$ in the second trial (36), and had inconsistent reactions across several southern U.S. locations (46), possibly indicating the difficulty in scoring this line as either TAN or RB.

Our results confirm that PI 462312 (Rpp3) and Hyuuga are not identical in their resistance to $P$. pachyrhizi; this finding is in agreement with Garcia et al. (11). To determine whether Rpp3 and $R p p ?$ (Hyuuga) are tightly linked genes or alleles of the same gene would require either a very large mapping population or cloning of either the Rpp3 or the Rpp?(Hyuuga) gene. We chose to focus on a third hypothesis, that Hyuuga carries the Rpp3 gene and a second, unlinked ASR resistance gene. We chose to address this hypothesis due to the readily available resources, namely Hyuuga (resistant) $\times$ Dillon (susceptible) RILs, the previously developed SSR map of this population, and the new information on $P$. pachyrhizi isolates that differentiate between PI 462312 and Hyuuga resistance.

Twenty-nine RILs previously shown to be resistant to a 2005 GFS of $P$. pachyrhizi (38) were challenged with isolate CO04-2, which can differentiate between PI 462312 and Hyuuga. Whereas all of the RILs were resistant to GFS, roughly half were susceptible when challenged with CO04-2, suggesting that all 29 of the RILs contain Rpp3 but only a subset has the second resistance gene that provides resistance to $\mathrm{CO} 04-2$. By inoculating 68 additional RILs with CO04-2 and using the resulting lesion type data for mapping, the second resistance locus was mapped to $\mathrm{GmO3}$ (LG-N) in the same genomic region as Rpp5 and has been designated as [Rpp5]_PI 506764.

ASR resistance in the four Rpp5 accessions was previously shown to map to Gm03 (11). Two of these accessions, PI 200487 and PI 471904, have more recently been shown to share identical SNP haplotypes to Hyuuga and PI 462312 on Gm06, where Rpp3 maps (37). In our study, both PI 200487 and PI 471904 reacted similarly to Hyuuga when challenged with each of the eight $P$. pachyrhizi isolates. In one replicate, an individual plant of PI 200487 and an individual plant of Hyuuga developed TAN lesions when inoculated with CO04-2 (Table 3). This is most likely the result of seed contamination.

The two other Rpp5 accessions yielded somewhat unexpected results. PI 200526 produced TAN lesions after inoculation with each of the eight isolates, indicating that the ASR resistance in this accession represents a different allele or an altogether different but tightly linked locus. PI 200456 (rpp5) plants developed TAN lesions following inoculation with isolates IN731 and LA04-1 (Table 3). When inoculated with CO04-2, VT05-1, and ZM01-1, the PI 200456 lines had some plants with TAN and some plants with $\mathrm{RB}$ reaction types (Table 3 ). These data, along with that collected from the Hyuuga, PI 200487, and PI 471904 inoculations, suggest that Rpp5/rpp5 drives resistance to CO04-2, VT05-1, and ZM01-1 while Rpp3 conditions the resistance to IN73-1 and LA04-1 observed in Hyuuga, PI 200487, and PI 471904.

The PI 200456 (rpp5) population also segregated when inoculated with isolates HW98-1 and SA01-1 (Table 3). Because this accession is highly inbred, this result is likely due to a seed mixture. This is not the first observation of PI 200456 responding unexpectedly when inoculated with $P$. pachyrhizi. Calvo et al. (5) crossed PI 200456 to accession PI 224270 (Howgyoku), which carries the recessive ASR resistance gene $r p p 2$, and the $\mathrm{F}_{2}$ progeny displayed a 3:1 RB/TAN segregation pattern, an unexpected ratio when crossing two recessive mutants (5). These data may collectively imply heterogeneity in the PI 200456 population or, possibly, the presence of a second gene conditioning ASR resistance, and it remains unclear whether the resistance in this accession is conferred by an allele of the Rpp 5 gene in PI 200487, PI 471904, and Hyuuga or an independent but tightly linked gene.

The identification and subsequent cloning of the Rpp3 and Rpp5 genes would be useful in further clarifying the number of resistance sources represented by the PI 462312-like, Hyuugalike, and Rpp5 accessions. Rpp 3 maps to $\mathrm{Gm06}$ between markers Satt460 and Sat_263 $(16,20)$. The Rpp?(Hyuuga) gene has been mapped to a 371-kb region between markers STS70887 and STS70923 on Gm06 and falls within the Rpp3 mapping region (37). Among the Rpp?(Hyuuga) and Rpp3 candidates within this region are seven genes encoding Toll/1nterlukinl receptor NBSLRRs (20,37). Another ASR resistance gene, Rpp4, has already been shown to encode a second class of NBS-LRRs, a CC-NBSLRR (34). Both types of NBS-LRR proteins have been shown to

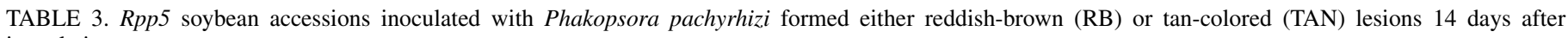
inoculations

\begin{tabular}{|c|c|c|c|c|c|c|c|c|}
\hline \multirow[b]{2}{*}{ Entry (gene) } & \multicolumn{8}{|c|}{ Isolates $^{\mathrm{a}}$} \\
\hline & $\mathrm{CO} 04-2$ & HW98-1 & IN73-1 & LA04-1 & SA01-1 & TW72-1 & VT05-1 & ZM01-1 \\
\hline Williams82 & TAN & TAN & TAN & TAN & TAN & TAN & $\mathrm{TAN}^{\mathrm{b}}$ & TAN \\
\hline PI 462312 (Rpp3) & TAN & $\mathrm{RB}^{\mathrm{b}}$ & $\mathrm{RB}$ & $\mathrm{RB}^{\mathrm{c}}$ & $\mathrm{RB}$ & TAN & TAN & $\mathrm{TAN}^{\mathrm{b}}$ \\
\hline Hyuuga (Rpp?[Hyuuga]) & $\mathrm{RB} / \mathrm{TAN}^{\mathrm{d}}$ & $\mathrm{RB}^{\mathrm{b}}$ & $\mathrm{RB}^{\mathrm{c}}$ & $\mathrm{RB}$ & $\mathrm{RB}$ & TAN $^{\mathrm{b}}$ & $\mathrm{RB}$ & $\mathrm{RB}$ \\
\hline PI 200456 (rpp5) & $\mathrm{RB} / \mathrm{TAN}^{\mathrm{e}}$ & $\mathrm{RB} / \mathrm{TAN}^{\mathrm{e}}$ & TAN & TAN & $\mathrm{RB} / \mathrm{TAN}^{\mathrm{e}}$ & TAN & $\mathrm{RB} / \mathrm{TAN}^{\mathrm{e}}$ & $\mathrm{RB} / \mathrm{TAN}^{\mathrm{f}}$ \\
\hline PI 200526 (Rpp5) & TAN & TAN ${ }^{\mathrm{g}}$ & $\mathrm{TAN}^{\mathrm{b}}$ & TAN $^{\mathrm{b}}$ & TAN & $\mathrm{TAN}^{\mathrm{b}}$ & TAN & TAN \\
\hline PI 471904(Rpp5) & $\mathrm{RB}$ & $\mathrm{RB}^{\mathrm{b}}$ & $\mathrm{RB}$ & $\mathrm{RB}$ & $\mathrm{RB}$ & TAN & $\mathrm{RB}$ & $\mathrm{RB}$ \\
\hline PI 200487(Rpp5) & $\mathrm{RB} / \mathrm{TAN}^{\mathrm{d}}$ & $\mathrm{RB}^{\mathrm{b}}$ & $\mathrm{RB}^{\mathrm{b}}$ & $\mathrm{RB}^{\mathrm{g}}$ & $\mathrm{RB}^{\mathrm{b}}$ & TAN & $\mathrm{RB}^{\mathrm{b}}$ & $\mathrm{RB}^{\mathrm{b}}$ \\
\hline
\end{tabular}

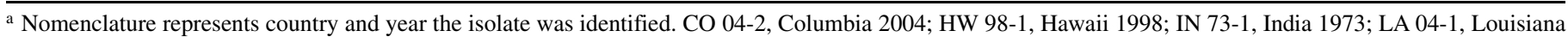
2004; SA 01-1, South Africa 2001; TW 72-1, Taiwan 1972; VT 05-1, Vietnam 2005; and ZM 01-1, Zimbabwe 2001. Data based on eight plants unless otherwise noted.

b Data based on seven plants scored in the two replicates per trial.

c Data based on six plants scored in the two replicates per trial.

d Seven plants scored as RB; one plant scored as TAN.

e Six plants scored as RB; two plants scored as TAN.

${ }^{\mathrm{f}}$ Five plants scored as RB; three plants scored as TAN.

$\mathrm{g}$ Data based on five plants scored in the two replicates per trial. 
function in disease resistance in other plant-microbe interactions (8-10).

Rpp5 has been mapped to $\mathrm{Gm03}$, between markers Sat_275 and Sat_280 (11). In total, $>80$ candidate genes are present in the Rpp5 region but none is annotated as an NBS-LRR. There are three putative serine/threonine kinase proteins at this locus, and serine/threonine kinases have also been implicated in disease resistance $(29,30)$.

Future studies to elucidate the Rpp 3 and Rpp5 genes include the use of reverse genetic approaches such as virus-induced-gene silencing (49), which was useful in the identification of Rpp4 (34).

\section{ACKNOWLEDGMENTS}

This work was partially funded by the United States Department of Agriculture-Agriculture Research Service, the Georgia Agricultural Experiment Stations, and grants from the United Soybean Board and the American Seed Trade Association. M. D. Kendrick was supported, in part, by the T. W. Edminster Postdoctoral Fellowship awarded to K. F. Pedley. We thank A. Ruck for her technical help in screening the cultivars for rust resistance; R. Nelson and T. Bedford for providing soybean germplasm from the USDA ARS Soybean Germplasm Collection; and B. Mills (University of Georgia Attapulgus Research and Education Center) and D. Phillips, D. Spradlin, and R. Miller (University of Georgia, Griffin Campus) for field and greenhouse evaluations of soybean lines for rust resistance.

\section{LITERATURE CITED}

1. Anderson, S. J., Stone, C. L, Posada-Buitraga, M. L., Boore, J. L, Neelam, B. A., Stephens, R. M., Luster, D. G., Frederick, R. D., and Pedley, K. F. 2008. Development of simple sequence repeat markers for the soybean rust fungus, Phakopsora pachyrhizi. Mol. Ecol. Res. 8:1310-1312.

2. Bonde, M. R., Melching, J. S., and Bromfield, K. R. 1976. Histology of the suspect-pathogen relationship between Glycine max and Phakopsora pachyrhizi, the cause of soybean rust. Phytopathology 66:1290-1294.

3. Bromfield, K. R. 1984. Soybean rust. Monogr. Ser. 11. American Phytopathological Society, St. Paul, MN.

4. Bromfield, K. R., Melching, J. S., and Kingsolver, C. H. 1980. Virulence and aggressiveness of Phakopsora pachyrhizi isolates causing soybean rust. Phytopathology 70:17-21.

5. Calvo, E. S., Kiihl, R. A. S., Garcia, A., Harada, A., and Hiromoto, D. M. 2008. Two major recessive soybean genes conferring rust resistance. Crop Sci. 48:1350-1353.

6. Cherry, E., and Peet, C. E. 1966. An efficient device for the rapid collection of fungal spores from infected plants. Phytopathology 56:11021103.

7. Christiano, R. S. C., and Scherm, H. 2007. Quantitative aspects of the spread of Asian soybean rust in the southeastern United States, 2005 to 2006. Phytopathology 97:1428-1433.

8. Dangle, J. L., and Jones, J. D. G. 2001. Plant pathogens and integrated defense responses to infection. Nature 411:826-833.

9. DeYoung, B. J., and Innes, R. W. 2006. Plant NBS-LRR proteins in pathogen sensing and host defense. Nat. Immunol. 7:1243-1249.

10. Dixon, M. S., Jones, D. A., Keddie, J. S., Thomas, C. M., Harrison, K., and Jones, J. D. 1996. The tomato $C f-5$ disease resistance locus comprises two functional genes encoding leucine-rich repeat proteins. Cell 84:451459.

11. Garcia, A., Calvo, E. S., de Souza Kiihl, R. A., Harada, A., Hiromoto, D. M., and Viera, L. G. E. 2008. Molecular mapping of soybean rust (Phakopsora pachyrhizi) resistance genes: Discovery of a novel locus and alleles. Theor. Appl. Genet. 117:545-553.

12. Goellner, K., Loehrer, M., Langenbach, C., Conrath, U., Koch, E., and Schaffrath, U. 2009. Phakopsora pachyrhizi, the causal agent of Asian soybean rust. Mol. Plant Pathol. 11:169-177.

13. GRIN. 2008. Germplasm Resources Information Network. National Germplasm Resource Laboratory, Beltsville, MD. www.ars-grin.gov/ npgs/index.html.

14. Hartman, G. L., Miles, M. R., and Frederick, R. D. 2005. Breeding for resistance to soybean rust. Plant Dis. 89:664-666.

15. Hartwig, E. E. 1986. Identification of a fourth major gene conferring resistance to soybean rust. Crop Sci. 26:1135-1136.

16. Hartwig, E. E., and Bromfield, K. R. 1983. Relationship among three genes conferring specific resistance to rust in soybeans. Crop Sci. 23:237239 .
17. Hennings, P. 1903. Some new Japanese uredinale. Hedwigia 42:107-108.

18. Hyten, D. L., Choi, I., Song, Q., Specht, J. E., Carter, T. E. Jr., Shoemaker, R. C., Hwang, E., Matukumalli, L. K., and Cregan, P. B. 2010. A high density integrated genetic linkage map of soybean and the development of a 1536 universal soy linkage panel for quantitative trait locus mapping. Crop Sci. 50:960-968.

19. Hyten, D. L., Hartman, G. L., Nelson, R. L., Frederick, R. D., Concibido, V. C., Narvel, J. M., and Cregan, P. B. 2007. Map location of the Rpp1 locus that confers resistance to soybean rust in soybean. Crop Sci. 47:837838 .

20. Hyten, D. L., Smith, J. R., Frederick, R. D., Tucker, M. L., Song, Q., and Cregan, P. B. 2009. Bulked segregant analysis using the GoldenGate assay to locate the Rpp3 locus that confers resistance to soybean rust in soybean. Crop Sci. 49:265-271.

21. Isard, S. A., Russo, J. M., and DeWolf, E. D. 2006. The establishment of a national pest information platform for extension and education. Plant Management Network. doi:10.1094/PHP-2006-0915-01-RV.

22. Keim, P., Olson, T. C., and Shoemaker, R. C. 1988. A rapid protocol for isolating soybean DNA. Soybean Genet. Newsl. 15:150-152.

23. Kitani, K., and Inoue, Y. 1960. Studies on the soybean rust and its control measure. Par 1. Studies on the soybean rust. Bull. Shikoku Natl. Agric. Exp. Stn. 5:319-342.

24. Kosambi, D. D. 1944. The estimation of map distances from recombination values. Ann. Eugen. 12:172-175.

25. Levy, C. 1995. Epidemiology and chemical control of soybean rust in Southern Africa. Plant Dis. 89:669-674.

26. Li, X., Esker, P. D., Pan, Z., Dias, A. P., Xue, L., and Yang, X. B. 2010. The uniqueness of the soybean rust pathosystem. An improved understanding of the risk in different regions of the world. Plant Dis. 94:796-806.

27. Manly, K. F., Cudmore, Jr., R. H., and Meer, J. M. 2001. Map Manager QTX, cross-platform software for genetic mapping. Mamm. Genome 12:930-932.

28. Marchetti, M. A., Melching, J. S., and Bromfield, K. R. 1976. The effects of temperature and dew period on germination and infection by urediospores of Phakopsora pachyrhizi in soybeans. Phytopathology 66:461463.

29. Martin, G. B., Bogdanove, A. J., and Sessa, G. 2003. Understanding the functions of plant disease resistance proteins. Annu. Rev. Plant Biol. 54:23-61.

30. Martin, G. B., Brommonschenkel, S. H., Chunwongse, J., Frary, A., Ganal, M. W., Spivey, R., Wu, T., Earle, E. D., and Tanksley, S. D. 1993. Map-based cloning of a protein kinase gene conferring disease resistance in tomato. Science 262:1432-1436.

31. McLean, R. J., and Byth, D. E. 1980. Inheritance of resistance to rust (Phakopsora pachyrhizi) in soybeans. Aust. J. Agric. Res. 31:951-956.

32. McLean, R. J., and Byth, D. E. 1981. Histological studies of the prepenetration development and penetration of soybeans by rust, Phakopsora pachyrhizi Syd. Aust. J. Agric. Res. 32:434-443.

33. Melching, J. S., Bromfield, K. R., and Kingsolver, C. H. 1983. The plant pathogen containment facility at Frederick, Maryland. Plant Dis. 67:717722.

34. Meyer, J. D. F, Silva, D. C. G., Yang, C., Pedley, K. F., Zhang, C., van de Mortel, M., Hill, J. H., Shoemaker, R. C., Abdelnoor, R. V., Whitham, S. A., and Graham, M. A. 2009. Identification and analyses of candidate genes for Rpp4-mediated resistance to Asian soybean rust in soybean. Plant Physiol. 150:295-307.

35. Michelmore, R. W., Paran, I., and Kesseli, R. V. 1991. Identification of markers linked to disease resistance genes by bulked segregant analysis: A rapid method to detect markers in specific genome regions by using segregating populations. Proc. Natl. Acad. Sci. USA 88:9828-9832.

36. Miles, M. R., Frederick, R. D., and Hartman, G. L. 2006. Evaluation of soybean germplasm for resistance to Phakopsora pachyrhizi. Plant Health Progress. doi: 10.1094/PHP-2006-0104-01-RS

37. Monteros, M. J., Ha, B. K., Phillips, D. V., and Boerma, H. R. 2010. SNP assay to detect the 'Hyuuga' red-brown lesion resistance gene for Asian soybean rust. Theor. Appl. Genet. 121:1023-1032.

38. Monteros, M. J., Missaoui, A. M., Phillips, D. V., Walker, D. R., and Boerma, H. R. 2007. Mapping and confirmation of the 'Hyuuga' redbrown lesion resistance gene for Asian soybean rust. Crop Sci. 47:829836.

39. Mueller, T. A., Miles, M. R., Morel, W., Marios, J. J., Wright, D. L., Kemerait, R. C., Levy, C., and Hartman, G. L. 2009. Effect of fungicide and timing of application on soybean rust severity and yield. Plant Dis. 93:243-248.

40. Ono, Y., Buritica, P., and Hennen, J. F. 1992. Delimination of Phakopsora, Physopella, and Cerotelium and their species on Leguminosae. Mycol. Res. 96:825-850.

41. Pham, T. A., Miles, M. R., Frederick, R. D., Hill, C. B., and Hartman, G. L. 2009. Differential responses of resistant soybean entries to isolates of Phakopsora pachyrhizi. Plant Dis. 93:224-228. 
42. Schneider, R. W., Hollier, C. A., Whitam, H. K., Palm, M. E., McKerny, J. M., Hernandez, J. R., Levy, L., and DeVries-Patterson, R. 2005. First report of soybean rust caused by Phakopsora pachyrhizi in the continental United States. Plant Dis. 89:774.

43. Silva, D. C. G., Yamanaka, N., Brogin, R. L., Arias, C. A. A., Nepomuceno, A. L., Mauro, A. O., Pereira, S. S., Noqueira, L. M., Passianotto, A. L. L., and Abdelnoor, R. V. 2008. Molecular mapping of two loci that confer resistance to Asian rust in soybean. Theor. Appl. Genet. 117:57-63.

44. Sydow, H., and Sydow, P. 1914. A contribution to the knowledge of the parasitic fungi of the island of Formosa. Ann. Mycol. 12:108.

45. Tan, Y. J., Yu, Z. L., and Yang, C. Y. 1996. Soybean Rust. China Agriculture Press, Beijing.

46. Walker, D. R., Boerma, H. R., Phillips, D. V., Schneider, R. W., Buckley, J. B., Shipe, E. R., Mueller, J. D., Weaver, D. B., Sikora, E. J., Moore, S.
H., Hartman, G. L., Miles, M. R., Harris, D. K., Wright, D. L., Marois, J. J., and Nelson, R. L. Evaluation of USDA soybean germplasm accessions for resistance to soybean rust in the southern United States. Crop Sci. 51:678-693.

47. Yang, X. B., Tschanz, A. T., Dowler, W. M., and Wang, T. C. 1991. Development of yield loss models in relation to reductions of components of soybean infected with Phakopsora pachyrhizi. Phytopathology 81:1420-1426

48. Yorinori, Y. T., Paiva, W. M., Frederick, R. D., Costamilan, L. M., Bertagnolli, P. F., Hartman, G. E., Godoy, C. V., and Junes, J. R. 2005. Epidemics of soybean rust (Phakopsora pachyrhizi) in Brazil and Paraguay from 2001 to 2003. Plant Dis. 89:675-677.

49. Zhang, C., Yang, C., Whitham, S. A., and Hill, J. H. 2009. Development and use of an efficient DNA-based viral gene silencing vector for soybean. Mol. Plant-Microbe Interact. 22:123-131. 